\title{
Delsuamy Vivekananda Medeiros (1938-2004): relações entre performer e contexto
}

Delsuamy Vivekananda Medeiros (1938-2004): relationships between performer and context

por Daniel Ribeiro Medeiros

\section{RESUMO}

Este artigo tem como objetivo ampliar a compreensão dos significados e relações que envolveram intérprete, meios de comunicação e público. Primeiramente, contextualiza-se a pesquisa no âmbito da musicologia brasileira. Após, são apresentados aspectos metodológicos (pesquisa em arquivos pessoal, institucional, análise de conteúdos), descrição de fontes documentais (matérias em jornais, programas de concertos, dentre outras), entremeados por respectiva fundamentação teórica. Na terceira parte são apresentadas as análises de conteúdos em matérias de jornais e programas de concertos. Nas considerações finais, a análise realizada nas fontes jornalísticas e o perfil do repertório são dialogados, no sentido de estabelecer relações entre performer e contexto. Conclui-se que a biografia de Delsuamy Vivekananda, no âmbito de sua atividade como concertista, constrói-se a partir da compreensão de um círculo cultural-musical onde os mesmos valores são compartilhados entre performer, imprensa e público.

Palavras-chave história do violão; Rio Grande do Sul; biografia;

Delsuamy Vivekananda Medeiros

ABSTRACT

This article aims to enlarge the understanding of the relationships and meanings that involved performer, media and public. First, our research will be contextualized within of brazilian musicology panorama. After, will be presented methodological aspects and description of documental sources with a theoretical foundation. In the third section, will be presented analisys of newspapers and concert programs contents. In the final considerations, the results of these methodological procedures will be put in dialogue, in the sense of to interpret the relations between performer and context. The Delsuamy Vivekananda Medeiros' biography is understood from cultural values that were shared between the press, performer and audience.

Keywords classical guitar history; Rio Grande do Sul; biography; Delsuamy Vivekananda Medeiros 


\section{Introdução}

Este trabalho faz parte de uma pesquisa iniciada em 2008, a qual culminou com uma dissertação cujo foco era analítico-composicional (no ano de 2010). Para tal, também foram levantadas informações no sentido de constituir uma breve biografia de Delsuamy Vivekananda Medeiros. Neste processo, foram identificadas, além da composição, outras três atividades: a docência, a atividade como performer e o trabalho em programas de rádio. 0 levantamento realizado em jornais da cidade de Pelotas apresentou registros frequentes de suas atividades musicais, principalmente no período correspondente à década de 1960. Mesmo ao término da dissertação, foi dada continuidade à busca de informações, proporcionando a atualização de dados, o mapeamento de atividades e ampliação de perspectivas temáticas e conceituais.

Essa pesquisa apoia-se, até o momento, fundamentalmente em fontes primárias, correspondendo ao contexto atual da pesquisa musicológica brasileira ligada a temáticas voltadas ao Sul:

A musicologia histórica ainda é uma área recente no Brasil, se comparado com outros países, tendo se iniciado de forma sistemática somente com os trabalhos de Kurt Lange nos anos 40. Nas décadas que seguiram a pesquisa musicológica manteve-se focada em alguns centros, como Minas Gerais, Rio de Janeiro e São Paulo; em seguida vieram os trabalhos sobre estados do Nordeste e Norte. Somente muito recentemente os estados do sul se viram incluídos nesse panorama, e o Estado de Santa Catarina ainda tem muitas fontes sobre sua memória musical a serem desveladas (HOLLER, 2007-2008, p.7).

Holler (2007-2008) também observa a importância da descentralização como forma de preencher lacunas historiográficas:

Até as últimas décadas a pesquisa musicológica no Brasil esteve voltada para a produção nos grandes centros, e praticamente ignorou as práticas em regiões periféricas. Trabalhos recentes envolvendo essas periferias têm demonstrado várias possibilidades de estudo, e o levantamento de informações mostram que ainda existem grandes lacunas na historiografia da música no Brasil (HOLLER, 2007-2008, p.9).

No entanto, tal cenário vem se alterando significativamente desde sua análise. Estudos acerca da música em Desterro (atualmente Florianópolis) cresceram quantitativamente. No Programa de Pós-graduação em Música da UDESC, por exemplo, são produzidas dissertações, bem como publicações na Revista do Centro de Artes da UDESC (DAPesquisa), que demonstram tanto a diversidade das práticas musicais em contextos sócio-históricos variados, bem como a diversidade temática dos trabalhos. São estudos que consideram os periódicos como "ecos da vida musical" em Desterro, no período do Brasil Império; irmandades e sociedades musicais na 
Primeira República; análise da recepção da ópera em Florianópolis em variados períodos (a partir da conjunção das visões anacrônica e sincrônica); dentre outras'.

No Rio Grande do Sul, destaca-se aqui o trabalho do Grupo de Pesquisa em Musicologia da UFPel, o qual desenvolve investigações ligadas à música na cidade de Pelotas, bem como no Conservatório de Música da UFPel. A produção do grupo vem contribuindo sistematicamente para a ampliação da musicologia brasileira:

Os trabalhos aqui impressos são um exemplo interessante dessa mudança de pensamento. Para além da eleição das divindades cuja chegada na Terra caberia ao pesquisador explicar, o Grupo de Pesquisa em Musicologia da UFPel partiu de uma necessidade real das pessoas envolvidas com a atividade musical no Sul do Brasil: como a prática e audição da música beneficiou as pessoas daquela época e como o musicólogo da atualidade poderia estender esse benefício para o presente? Afinal, não foram os grandes gênios que trouxeram os benefícios da prática e da audição de música para os moradores das regiões estudadas pelo Grupo de Pesquisa, mas sim as instituições dedicadas a essa arte e, sobretudo, a grande quantidade de pessoas envolvidas nesse processo. Nessa direção foram estruturadas ações que partiam das pessoas do presente e não dos mitos civilizatórios que nos poderiam ter sido impostos. Foram então incluídos, nessa abordagem, vários fenômenos relacionados à vida das sociedades daqueles tempos $e$ lugares, não importando se eles possuíam ou não alguma posição na suposta e divina hierarquia civilizadora (CASTAGNA, 2010, p.5).

Castagna (2010) também destaca a ampliação de perspectivas que o Grupo apresenta:

Provavelmente já estejamos próximos da cura desse sentimento de exclusão de nós mesmos e possamos nos dedicar mais, como fez o Grupo da UFPel, à inclusão de outros aspectos humanos a uma musicologia mais sistêmica e mais complexa: outras cidades do Sul, outras regiões do Brasil, outras regiões americanas, outras regiões do mundo, outros habitantes do Sul, do Brasil, das Américas e do Mundo, outros espaços de circulação da música, outros jeitos de se cantar e tocar, outros meios ou instrumentos de produção musical, outras finalidades da prática musical, outras funções da música, outras músicas, outras épocas, outros tipos de pessoas, outras idades de pessoas, outras preferências das pessoas, outras relações entre pessoas, outras pessoas, outras necessidades de música, outras necessidades de musicologia, outras necessidades... (CASTAGNA, 2010, p.6-7).

Embora tal cenário tenha se expandido, ainda há muito que fazer. E é dentro deste panorama que nossa pesquisa se insere. Investigar o trabalho de Delsuamy Viveka-

1 Narciso e Eco: os periódicos como reflexos e ecos da vida musical em Desterro (2012), Sociedade Musical Amor à Arte: um estudo histórico sobre a atuação de uma banda em Florianópolis na Primeira República (2011), dentre outras. 
nanda Medeiros vai além da "eleição das divindades" como únicos agentes dignos de serem mencionados, pois lida com uma outra pessoa envolvida com a música no Sul do Brasil"; vai além da ideia única de que somente os "gênios da música" proporcionaram o desenvolvimento artístico, pois trata de um agente envolvido diretamente com a música na cidade de Pelotas; vai além dos agentes inseridos no contexto dos grandes centros, pois considera uma pessoa que habitou o Sul, inserida em outra região do Brasil; e assim por diante.

\section{Descrição de fontes, panorama metodológico e aspectos teórico-conceituais}

inicialmente, foram encontrados apenas quatro registros acerca de Vivekananda, tornando o levantamento de fontes primárias como processo fundamental. Livros como História Iconográfica do Conservatório de Música da UFPel (2005) e História do Conservatório de Música de Pelotas (1992), apresentam poucas informações, assim como as breves citações em artigos nas revistas Assovio e Violão e Mestres. A partir deste diagnóstico, foram iniciadas prospecções tanto no arquivo pessoal do músico², como no acervo de jornais do Centro de Documentação e Obras valiosas (CEDOV) da Bibliotheca Pública Pelotense?.

Do arquivo pessoal foram consultados: cópias do curriculum, cartas, matérias de jornais, programas de concertos, dentre outros documentos. 0 curriculum dispõe de informações como: atividades artístico-profissionais como recitais, apresentações em rádios e emissoras de televisão, escolas de música e conservatórios; instituições onde trabalhou como professor de violão; prêmios recebidos, menções honrosas recebidas por cartas; dentre outros itens mencionáveis em um currículo.

Na Bibliotheca Pública Pelotense foram consultados jornais da cidade de Pelotas. A importância deste tipo de fonte documental ocorre na medida em que "apresentam informações diversificadas envolvendo a prática musical, tais como artigos, folhetins, leis e anúncios" (VICENZI; HOLLER, 2007-2008, p.1), bem como os programas de concertos, cuja análise pode levar a "conclusões sobre o gosto musical na época, e sua variação através das décadas" (VICENZI; HOLLER, 2007-2008, p.7).

Por outro lado, existe a dimensão crítica necessária ao processo de leitura dos conteúdos jornalísticos:

Os jornais são uma fonte primária relevante para a pesquisa histórico-musicológica, mas para uma melhor interpretação desses documentos,

20 qual se encontra em posse de seus familiares. Agradeço desde já os familiares pela disponibilidade e compreensão da importância deste trabalho.

3 A Bibliotheca Pública Pelotense encontra-se no seguinte endereço: Praça Coronel Pedro 0sório, 103, Centro, Pelotas-RS. 
é necessário estar ciente de que as informações encontradas nos jornais refletem de forma limitada os acontecimentos musicais, por não serem descrições precisas e imparciais, além de excluir a música feita pelas camadas mais populares. Portanto, é importante saber por quem eram escritos esses jornais e que ideais e interesses tinham as pessoas que detinham 0 poder da imprensa na época (GONÇALVES; HOLLER, 2009-2010, p.355).

Cerqueira et al. (2008), por sua vez, destacam o tratamento destes documentos como testemunhos das percepções de seus produtores:

0 levantamento de dados nos jornais antigos, buscando notícias, críticas e aspectos da vida musical, está permeado pelo conceito de história imediata, que, conforme o historiador Jean Lacouture (1988: 217), 'não tende apenas a encurtar os prazos entre a vida das sociedades e sua primeira tentativa de interpretação, mas também a dar a palavra aos que foram os atores dessa história'. 0 jornal, portanto, nos colocaria em contato direto com opiniões e percepções contemporâneas aos acontecimentos. Além disso, dada a sua característica de serem meios de comunicação de massa, muito mais do que trazerem aos historiados narrativas acontecimentais, possibilitam o acesso ao plano das representações, portanto, a um nivel de subjetividade: como a sociedade da época via a si mesma e queria ser vista (CERQUEIRA et al., 2008, p.125).

Mais tarde, acrescentam que através da leitura das matérias de jornais, pode-se:

[...] acessar formas de representação da vida musical, bem como dos valores associados à música na vida social da época: supomos que estas matérias de jornal traziam tanto a visão dos que decidiam, naquele momento, o que era digno de ser notícia, bem como os anseios daqueles que os consumiam e que faziam parte da vivência cotidiana de socialização da música na sociedade pelotense das primeiras décadas do século XX (CERQUEIRA et al., 2008, p.126).

As matérias levantadas apresentam uma tipologia básica: artigos divulgativos e críticas de concertos. Os artigos divulgativos apresentam os seguintes conteúdos:

\begin{tabular}{|l|l|}
\hline Tipo de informação corrente & Conteúdo \\
\hline Breve currículo descritivo & $\begin{array}{l}\text { Informações a respeito da cidade natal; chegada à } \\
\text { Pelotas; seu antigo professor; apresentações realizadas; } \\
\text { dentre outras informações. }\end{array}$ \\
\hline Comentários laudatórios & $\begin{array}{l}\text { Ceralmente relacionados às qualidades técnico-expressi- } \\
\text { vas do instrumentista. }\end{array}$ \\
\hline Programa & $\begin{array}{l}\text { Relação de obras e compositores que compunham os } \\
\text { programas dos concertos. }\end{array}$ \\
\hline
\end{tabular}

Figura 1. Tabela com os tipos de informações e conteúdos vinculados aos artigos divulgativos 
Os programas de concertos apresentam basicamente dois tipos de informação: currículo descritivo do programa. A análise dos programas se torna importante aqui, uma vez que em diálogo com o conteúdo das matérias, auxilia no processo reflexivo acerca dos valores estéticos e possiveis relações entre performer e contexto:

Realizar o estudo de programas de concerto [...] de concertistas, aliado ao levantamento de críticas e notícias publicadas nos jornais [...], significa compreender que o repertório escolhido por um artista [...] reflete a forma como as obras musicais foram recebidas por um determinado público em seu momento histórico. Analisar as relações de recepção, [...] significa oferecer ferramentas para a reflexão sobre as práticas musicais no Rio Grande do Sul, no âmbito educacional e artístico (CERQUEIRA et al., 2008, p.128-129).

0 caráter fragmentado e disperso das informações trouxe a necessidade de dialogar fontes. Este trabalho de organização é necessário dentro do próprio contexto da musicologia brasileira. Embora esteja se direcionando cada vez mais para sua fase interpretativa, os processos característicos da musicologia positivista ainda são necessários:

Essa mudança está associada ao início da superação do modelo positivista que predominou na musicologia brasileira até meados da década de 1990 e à procura de novas teorias que possam explicar o significado dos fenômenos estudados. Isso não significa, entretanto, que a fase positivista - bastante preocupada com a organização de informações - tenha produzido suficiente material para subsidiar interpretações e reflexões de fôlego sobre o passado musical brasileiro. Pelo contrário, ainda resta muito trabalho a ser feito no que se refere à catalogação de acervos, edição de obras, organização e sistematização de fontes, o que impõe à nova musicologia a responsabilidade de desenvolver trabalhos sistemáticos e, ao mesmo tempo reflexivos. Se a nova musicologia possui maior amplitude de ação em relação às tendências que a precederam, é inegável a enorme responsabilidade que acabou sendo transmitida aos musicólogos que vêm atuando a partir da década de 1990, sobretudo à geração que iniciou o seu trabalho a partir dessa época (CASTAGNA, 2008, p.52).

\section{Relações entre performer, imprensa e repertório}

\subsection{0 concertista na imprensa}

0 primeiro registro levantado data de 11 de junho de 1960 (Diário Popular):

DELSUAMY VIVEKANANDA, HOJE, NA SOC. LIBANESA

Hora de arte a cargo do jovem e exímio violonista

Hoje, à noite, na Sociedade Libanesa de Pelotas, atendendo a pedido do 
Presidente dr. Fuad Selaimen e outros membros da Diretoria, apresentar-se-á aos associados daquela prestigiosa agremiação o exímio violonista Delsuamy Vivekananda Medeiros, professor do Conservatório Rossini, desta cidade.

Jovem, de 22 anos de idade, Delsuamy é natural de Pelotas, mas se criou em Bagé, onde residem seus exmos. pais, fixando-se, novamente, aqui, há pouco mais de um ano. Apaixonado, desde a infância, pelo violão, já aos oito anos fazia as primeiras posições até que, há quatro anos atrás, passou a dedicar-se sériamente ao estudo do difícil instrumento que consagrou Andrés Segóvia, sendo, hoje, embora sem concluir ainda o longo curso ouvido com extraordinária admiração na execução das clássicas composições dos mais famosos violonistas do mundo.

Hoje, portanto, teremos uma promissora noitada de arte, quando Delsuamy Vivekananda, com a primorosa técnica e o sentimento que sabe imprimir às suas interpretações, colherá, por certo, os mais fartos aplausos da seleta família libanesa de Pelotas (DELSUAMY vivekananda, hoje, ..., 1960, p.4).

0 segundo data de 3 de julho de 1960:

Executar música séria ao violão, é segundo críticos de arte, uma das mais dificeis interpretações, pois, o instrumento requer muito estudo e apreciável temperamento artístico, na dificuldade de seu manejo e emissão.

Pelotas tem agora frequentemente oportunidade de ouvir através de rádios locais Delsuamy V. Medeiros que no violão tem feito bonitas e sentidas interpretações, que o destacam no panorama artístico da cidade.

Muito em breve, teremos oportunidade de apreciar sua arte privilegiada em um concêrto, e tôda cidade poderá medir a técnica do jovem e inteligente musicista que faz aqui notícia e conversa com seu instrumento empregado num assunto sério - música de câmara (NOTAS de arte, 1960, p.4).

Na divulgação do concerto na Sociedade Libanesa de Pelotas, embora tenha sido o primeiro registro encontrado, deixa claro que Vivekananda já possuía uma agenda de apresentações na cidade, uma vez que "agora" era a vez da "seleta família libanesa" apreciar sua arte. A segunda matéria faz menção às audições em emissoras de rádio de Pelotas, o que demonstra que sua circulação não estava circunscrita somente às salas de concertos, salões, mas também a outros ambientes. A difusão radiofônica provavelmente implicou em uma divulgação abrangente de seu nome na cidade, contribuindo também para o conhecimento de seu estilo performático, repertório, bem como outros aspectos.

Os conteúdos, geralmente dão conta do destaque à percepção da dificuldade de manuseio técnico e expressivo do instrumento e a relação de "maestria" que Vivekananda possuía neste quesito. Sua imagem, vinculada a estes valores, sugere que o músico atendia, de certa forma, às expectativas que o público tinha a respeito dos concertos. Além disso, 
no âmbito das divulgativas, chama atenção a criação de expectativa acerca das oportunidades de se estar presente às suas apresentações. Ou seja, nota-se que a imprensa tende a destacar aos seus leitores a importância de testemunharem os concertos de um músico da cidade que se destaca por suas qualidades expressivas e técnicas.

No artigo Delsuamy atuou na PRH-2 e na TV-Piratini: P. Alegre temos:

A convite da Rádio Farroupilha e da TV-Piratini, de Pôrto-Alegre, passou o fim de semana naquela capital, regressando ontem, a esta cidade, o conhecido violonista pelotense Delsuamy Vivekananda Medeiros, professor do Conservatório Rossini de Pelotas, que aqui tem atuado em diversas oportunidades e colhido justos aplausos.

Delsuamy apresentou-se em programas da PRH-2, sexta, sábado e domingo, e, segunda-feira à noite, em especial exibição, na TV-Piratini.

Em todas essas oportunidades, o exímio violonista pelotense colheu os mais fartos aplausos, encantando, com a sua arte, rádio-ouvintes e telespectadores de Pôrto Alegre, sendo de ressaltar-se o fato, inédito na vida da TV-Piratini, de ter sido prolongado o programa atendendo a inúmeros pedidos.

Em palestra com o repórter, ontem, Delsuamy Medeiros mostrou-se satisfeito com a acolhida que mereceu de parte de funcionários e direção da Rádio Farroupilha e TV-Piratini, onde deverá voltar a apresentar-se, dentro de breve (DELSUAMY atuou na PRH-2..., 1960, p.4).

Pode-se dizer que o violonista possuía um considerável apoio da mídia local na divulgação de seus concertos. Pode-se tomar este aspecto como de extrema importância para o estabelecimento de sua atividade artística e consolidação de sua imagem perante o público. Nota-se que à época o violonista era notícia na imprensa local, uma vez que suas apresentações em outras cidades eram recorrentemente acompanhadas e publicadas.

Chama atenção a relevância dada ao concerto de 18 de junho de 1963 no Conservatório de Música de Pelotas. Este concerto é considerado como sendo sua "estréia oficial" no referido estabelecimento. É interessante observar o clima de expectativa que é construído: "[...] Reina invulgar expectativa em tôrno dessa noitada artística, eis que os apreciadores da arte estarão a apreciar uma apresentação com que raramente é brindada nossa platéia, qual seja, a de recital de violão. [...]" (HOJE o recital de violão..., 1963, p.4).

Quando o autor (anônimo) faz menção à "nossa platéia", certamente refere-se ao perfil do público tradicional do Conservatório de Música de Pelotas4. A expectativa em torno do concerto é ressaltada pelo mesmo na medida em que salienta o fato

4 Até o momento, não foram encontrados estudos acerca do perfil sócio-econômico do público que comumente frequentava os concertos no Conservatório de Música à época. 
de que a seleta plateia do Conservatório é raramente brindada com concertos de violão. A importância deste recital é ampliada ao observarmos a repercussão na imprensa. Na contracapa da edição de 21 de junho de 1963, há a inserção da divulgação (com foto de Vivekananda) da crítica escrita por Sóls:

RECITAL DE VIOLÃO - Continua repercutindo nos círculos artísticos locais o recital de violão, a cargo do prof. Delsuamy Vivekananda, levado a efeito á noite de terça-feira última, no auditório do Conservatório de Música de Pelotas. (Leia na página 4 comentários especializados do nosso cronista "Sol") (RECITAL de violão ..., 1963, contracapa).

Abaixo, trecho da crítica publicada pelo cronista:

0 violão ou guitarra, que até os primeiros anos dêste século aqui pontificava nas serenatas boêmias, como acompanhador das langorosas modinhas da época, desde 1912 - com o aparecimento do paraguaio Agustin Barrios - passou a ser respeitado como verdadeiro instrumento de salão que sempre iôra [sic] na legendária Espanha, num crescendo de admiração que, depois, concertistas como Josefina Roblêdo, Oyangúren [sic], Bárrios [sic] (outra vez), Segóvia, Carnevale [sic], Maria Luiza Anido, Carrión, etc., vieram consagrar definitivamente, impondo-o ao devido aprêço de nossos diletantes.

Agora, a noite de 18 de junho de 1963 ficará assinalada, nos anais do Conservatório de Pelotas, como sendo o da estréia, ali, do jovem e novel guitarrista bagéense Delsuamy Vivekananda (nome esotérico), que muito condignamente vem enfileirar-se àqueles eminentes colegas seus, ao procurar seguir-lhes os passos, já que pisou com o pé-direito na estrada sem-fim da Arte.

Autêntica vocação musical, bêm que ele mereceu os entusiásticos quão espontâneos aplausos que lhe tributou o muito numeroso e atento auditório dêsse agradabilíssimo saráu, ao surpreender-nos êle com sua técnica segura e límpida, através de umas sonoridades que primaram por uma bonita fatura (nítida, sôlta e bonita), a serviço de um intérprete inteligente e emotivo, de exemplar contrôle nervoso [...] (SóL, 1963, p.4).

Sól demonstra conhecimento acerca dos concertos de violão em Pelotas e seus respectivos personagens, traçando um panorama histórico para fins de contextualização. Provavelmente, o cronista tenha assistido às apresentações de todos estes músicos. É importante destacar também a relação sócio-cultural que o autor faz quando comenta sobre o caráter "langoroso" do contexto musical ao qual o violão estava circunscrito. Conforme seu comentário, o violão passou a ser respeitado

5 Pseudônimo do crítico musical Waldemar Coufal. Diversas críticas suas encontram-se em muitas edições do jornal Diário Popular (Pelotas). 
como instrumento apreciável em salas de concerto a partir da primeira visita de Agustín Barrios, em 1912, sendo comparado com o status que o instrumento já possuía na Espanha, por exemplo. Este tipo de associação do violão com um imaginário ibérico é recorrente em suas críticas. Sól também demonstra conhecimento acerca das confusões terminológicas e organológicas relativas ao instrumento quando inicia o texto com "o violão ou guitarra". Chama atenção o fato de o cronista colocar Vivekananda "enfileirado" aos "eminentes colegas". Isso soa como uma espécie de "aceite" que o jovem "guitarrista" recebeu após sua estreia oficial no auditório do Conservatório de Música.

0 destaque às virtudes do instrumentista finaliza o "atestado" da qualidade daquele que acabava por estrear. 0 foco sobre quesitos como desenvoltura técnica, sonoridade, inteligência, emotividade e "contrôle nervoso" mostram elementos que chamaram atenção de Sól, e que certamente se constituíam como critérios de avaliação. Dessa forma, o caráter de "estréia oficial" pode estar ligado à apresentação de um violonista que residia na cidade e que possuía as condições artísticas necessárias para ser considerado como referencial de concertista de violão, a partir de critérios valorizados à época.

0 apoio incondicional da imprensa pode ser exemplificado na matéria abaixo:

Há mais ou menos seis anos, chegava a Pelotas, procedente de Bagé, um moço que viria a lograr a consagração da platéia pelotense na sua arte. Em sua bagagem, trazia sob o braço um violão e no espírito um grande $e$ nobre ideal.

Começou sua carreira artística como professor do Conservatório de Música Rossini. Daí por diante, apresentou-se várias vezes em Pôrto Alegre, em teatros, emissoras de rádio e de televisão. Em 1963, realizou um recital no Conservatório Municipal de Música, desta cidade, sendo calorosamente aplaudido. Atuou, posteriormente, em inúmeras oportunidades. E, agora, na semana que passou, Vivekananda realizou três recitais, respectivamente, no Clube Cultural Fica Aí Pra Ir Dizendo, no auditório do Colégio São José e na sede da Asociação Atlética Banco do Brasil, onde encantou os amantes da arte musical, sendo, inclusive, aplaudido de pé, por uma assistência de cêrca de quinhentas pessoas, como aconteceu no auditório do citado estabelecimento de ensino, gentilmente cedido para a memorável realização artística.

Foi, portanto, uma vitória que Vivekananda alcançou, dupla vitória, aliás, já que, sendo 'prata da casa', soube conquistar a simpatia e o aplauso consagrador da platéia pelotense. [...] (DELSUAMr vivekananda foi..., 1965, p.4).

Essa matéria apresenta uma mudança no teor do texto em relação às outras: Vivekananda já não parece mais ser um músico que estava buscando espaço no meio musical pelotense, mas que já estava consolidado como artista local. É interessante notar que a matéria começa com uma breve contextualização da trajetória 
do músico, demonstrando o acompanhamento de suas movimentações.

A mesma matéria também veicula a notícia da ida de Delsuamy Vivekananda ao Uruguai. No último parágrafo, destaca: “Delsuamy Vivekananda viajou na manhã de hoje para Montevidéu, onde se apresentará em salas de concêrto e outros ambientes de arte [...]" (DELSUAMY vivekananda foi..., 1965, p.4). Na matéria Delsuamy Vivekananda: una passion, la guitarra, está registrada a estada do violonista em Montevidéu:

Se llama Delsuamy Vivekananda [...]. Estuvo anoche en nuestra redacción y pudimos escucharlo en un extraño concierto. Entre el teclear de las máquinas, los ruidos de las linotipos y el apressuriamento de la hora del cierre de la primera edición, Vivekananda comenzó com LUAR DO CERTAO (del folklore del nordeste brasileño) y continuó com PRELUDIO No 1 de Bach, MINUETO de Beethoven, ASTURIAS de Albéniz, y su guitarra fué de a poco imponiéndose al ruido ambiente. [...] Aquí estará una semana y sólo actuará mañana sábado en una radioemisora y en el centro folklórico Teluria (DELSUAMY vivekananda: una passion, la guitarra, [1965], p.[s/p]) .

A emissora de rádio à qual a matéria cita é, segundo confronto dos dados, a rádio El Espectador, sendo a apresentação realizada no dia 12 de junho de 1965 (sábado):

Notícia procedente de Montevidéu, onde se encontra há uma semana o festejado guitarrista Delsuamy Vivekananda, informa que o jovem instrumentista está brilhando na capital uruguaia e que hoje, às 20,07 horas, atuará na Radio 'El Espectador', [...] (DELSUAMY Vivekananda Atuará, Hoje, ..., 1965, p.4).

0 retorno a Pelotas está registrado na matéria Aulas de violão, demonstrando, mais uma vez, o amplo acompanhamento da circulação do violonista a outras localidades, o que reforça a consideração de que Vivekananda era notícia: "Retornando de suas férias, durante as quais realizou recitais nesta cidade [Pelotas] e em Montevidéu, o prof. Delsuamy Vivekananda voltará a ministrar aulas aos seus alunos" (AULAS de violão, 1965, p.4).

Em edições do Diário Popular do ano de 1966 foram encontrados registros de 3 apresentações. 0 primeiro diz respeito ao anunciado concerto no auditório do Colégio Gonzaga. São inserções em quatro edições do jornal, as quais demonstram a prática da criação de grande expectativa: "[...] 0 concêrto vem sendo aguardado

6 Conforme o currículo de Delsuamy Vivekananda, tal artigo é do jornal uruguaio El Paiz. Essa informação é corroborada por Alfredo Escande, pesquisador e ex-aluno de Abel Carlevaro. Conforme 0 uruguaio: "El recorte [do jornal] parece ser, efectivamente, del diario El País (por el tipo de letra y diagramación)" (ESCANDE, 2009, mensagem pessoal).

7 GUITARRISTA vivekananda. Diário Popular, Pelotas, 19 jun. 1966, p.4; RECITAL de delsuamy. Diário Popular, Pelotas, 24 jun. 1966, p.4; RECITAL de delsuamy amanhã. Diário Popular, Pelotas, 5 jul. 1966, p.4; CONCÊRTO de violão. Diário Popular, Pelotas, 6 jul. 1966, p.4. 
com geral expectativa pelo mundo artístico pelotense, onde Delsuamy conta com inúmeros fans, graças aos seus exitosos recitais anteriores" (RECITAL de delsuamy, 1966, p.4).

0 segundo diz registro diz respeito a uma série de recitais a serem apresentados na Semana de Porto Alegre de 1966:

Convidado pela Divisão de Cultura da Prefeitura Municipal de Pôrto Alegre, por indicação especial do Grêmio Villa-Lobos, violonista Delsuamy Vivekananda, seguiu, ontem, para aquela capital, a fim de tomar parte em concertos a serem oferecidos ao público por ocasião da "Semana de Pôrto Alegre".

Como vem fazendo desde anos anteriores, a Prefeitura da capital, por intermédio de sua Divisão de Cultura, de que atualmente é titular a prof. ${ }^{a}$ Eny Camargo, oferecerá durante a próxima "Semana de Pôrto Alegre" uma série de recitais públicos, três dos quais a cargo do festejado violonista pelotense, que atuará nos dias 6,7 e 12 do corrente (VIVEKANANDA: 3 recitais na "semana de p. alegre", 1966, p.4).

Porém, chama atenção o registro de uma turnê que teria sido realizada por Delsuamy Vivekananda. 0 texto intitulado Delsuamy Vivekananda fará excursão no mês vindouro! apresenta o seguinte trecho: “[...] Iniciará, então, uma 'turnée' pelas principais cidades do país, até onde levará sua arte, já tão difundida em nosso meio [...]" (DELSUAMY Vivekananda fará excursão..., 1966, p.4). No entanto, após ampla pesquisa em edições do jornal Diário Popular deste mês, não foram encontradas mais referências a respeito desta turnê.

0 ano de 1967 é marcado, até o momento, pela falta de registros referentes a concertos. Somente um programa foi encontrado, o qual se refere ao recital no Teatro São Pedro (Porto Alegre), em 27 de março. Os únicos registros encontrados em edições do Diário Popular referem-se somente ao início do curso de violão: ministrado por Vivekananda, no Conservatório de Música de Pelotas.

\subsubsection{Considerações preliminares}

0 levantamento acima apresenta um cenário em que Delsuamy Vivekananda recebeu um considerável apoio por parte da imprensa. Além disso, destaca-se aqui a contribuição que emissoras de rádio locais deram neste aspecto. Dessa forma, pode-se imaginar que seu nome e imagem eram consideravelmente difundidos na cidade, pelo menos em se tratando do público leitor e ouvinte de jornais e

8 DELSUAMY vai ensinar violão no conservatório. Diário Popular, Pelotas, 21 abr. 1967, p.4; INSCRIÇÕES para o curso de violão no conservatório. Diário Popular, Pelotas, 23 abr. 1967, p.4; CURSO de violão. Diário Popular, Pelotas, 281 abr. 1967, p.4; CURSO de violão: começa hoje. Diário Popular, Pelotas, 3 mai. 1967, p.4. 
rádios. A linguagem utilizada na confecção dos artigos a respeito do destaque das qualidades técnicas e expressivas do instrumentista são uma constante; o clima de expectativa que era criado através das notícias publicadas dias antes dos concertos reforçam a ideia de um considerável apoio da mídia. Além disso, a ampla cobertura, a qual não estava restrita somente à divulgação de concertos locais e publicação de críticas e crônicas, também diz respeito à busca e veiculação de notícias do concertista em outras cidades e até mesmo em outros países.

\subsection{Análise do repertório9}

A leitura dos programas de concertos traz uma ideia sobre os conteúdos estéticos aos quais Delsuamy Vivekananda esteve ligado em sua prática como concertista. Além disso, proporcionam a compreensão do seu perfil como performer, ou seja, como o repertório contribui para o processo de construção e consolidação de sua identidade musical. Se pensarmos que tal atividade envolve uma gama abrangente de relações envolvidas entre músicos e contextos, devemos considerar também que a escolha do repertório por parte do musicista não está desvinculada do processo de recepção ligado ao público. Em outras palavras, pode-se pensar 0 intérprete constitui-se através da relação entre o perfil do seu repertório (suas concepções e valores relacionados ao contexto), capacidade técnico-expressiva (muitas vezes ligada ao aspecto visual, gestualidade do aspecto performático, ou seja, vários aspectos envolvendo a percepção do ponto de vista sinestésico, muitas vezes ligada à recepção por parte do público e da análise do conteúdo gestual das obras), assim como várias outras relações intersubjetivas que se estabelecem com o público e meios de comunicação.

Nogueira (2010) apresenta algumas reflexões a respeito deste tipo de processo no contexto pianístico:

[...] creemos adecuado pensar que el repertorio elegido por el músico [...] es ya la primera forma de recepción, puesto que de toda la literatura para el instrumento, ese selecciona las obras que irán representar su discurso y a él mismo delante del público. [...] entendemos que la elección de las obras por los pianistas puede ser considerada como la primera forma de recepción musical, una vez que antes de elegir como tocar, hay que elegir el que tocar (NOGUEIRA, 2010, p.180).

Mais tarde, observa:

[...] entendemos los pianistas como categoría de intérpretes, cuya relación con el repertorio musical depende de una elección individual, que, por su turno, depende de la orientación que han recibido, de la forma como

9 Optou-se pela não-inserção da produção composicional de Vivekananda, uma vez que é tratada em nossa dissertação e em artigos já publicados. 
han construido su relación con el público, y con su concepción de la función del músico, entre otras.

Una vez que para esos conciertos no existe la necesidad de aprobación formal de las elecciones del músico por parte de un director o productor musical, podemos sugerir la hipótesis de que los criterios para elección de las obras hayan sido de cada intérprete, según su formación y conceptos (NOGUEIRA, 2010, p.180).

Dessa forma, entendemos que para uma compreensão mais aprofundada acerca da identidade musical de Viveknanda como performer é necessário observar como o repertório, enquanto uma eleição individual e dependente de valores articulados através da orientação recebida em seu processo formativo e de sua relação com 0 público, representa seu discurso e sua imagem.

Os programas analisados até o momento apontam para um perfil de repertório que não se alterou ao longo da década de 1960. Embora o número de programas levantados não represente a totalidade das apresentações realizadas, acredita-se que o padrão não tenha se alterado. A tabela abaixo mostra a relação de peças encontradas em seus programas de concertos:

\begin{tabular}{|l|l|l|}
\hline \multicolumn{2}{|c|}{ Programas de concertos da década de $1960(1963 ; 1965 ; 1966 ; 1967 ; 1968)$} \\
\hline Compositores & Obras & Frequência \\
\hline Abel Fleury (1903-1955) & - Estilo pampeano & 3 \\
\hline Andrés Segovia (1893-1987) & - Prelude in chords & 4 \\
\hline $\begin{array}{l}\text { Antônio Sinopoli } \\
\text { (1878-1964) }\end{array}$ & - Vidalita (canção argentina) & 1 \\
\hline $\begin{array}{l}\text { Catulo da Paixão Cearense } \\
\text { (1863-1946) }\end{array}$ & - Luar do Sertão & 2 \\
\hline $\begin{array}{l}\text { Dilermando Reis } \\
\text { (1916-1977) }\end{array}$ & - Valsa brasileira & 1 \\
\hline Felix Mendelssohn (1809-1847) & - Gôndola Veneciana - Barcarola Op.19 nº 6 & 3 \\
\hline Fernando Sor (1778-1839) & - Minueto da Sonata Op. 25 & 1 \\
\hline $\begin{array}{l}\text { Francisco Tárrega } \\
\text { (1852-1909) }\end{array}$ & - Recuerdos de Alhambra (Trêmolo) & 4 \\
\hline
\end{tabular}


Delsuamy Vivekananda Medeiros (1938-2004):

relações entre performer e contexto

\begin{tabular}{|c|c|c|}
\hline Compositores & Obras & Frequência \\
\hline \multirow[t]{2}{*}{ Franz Schubert (1797-1828) } & - Serenata & 4 \\
\hline & - Ave Maria & 1 \\
\hline $\begin{array}{l}\text { Friederich Händel } \\
(1685-1759)\end{array}$ & - Coral (transcrição de Francisco Tárrega) & 2 \\
\hline G. Sagreras (1838-1901) & - Uma lágrima (Delírio) & 3 \\
\hline Heitor Costa (----)* & - Romanza & 5 \\
\hline Isaías Sávio (1900-1977) & - Batucada (cenas brasileiras) & 1 \\
\hline Isaac Albéniz (1860-1909) & - Astúrias (Leyenda) & 4 \\
\hline \multirow{3}{*}{$\begin{array}{l}\text { J. Sebastian Bach } \\
(1685-1750)\end{array}$} & - Prelúdio $n^{0}{ }_{1}$ & 7 \\
\hline & - Chacone (fragmento) & 3 \\
\hline & - Dois Prelúdios & 1 \\
\hline $\begin{array}{l}\text { Jean-Philippe Rameau } \\
(1682-1764) \text {. }\end{array}$ & - Minuetto & 1 \\
\hline Juan Rodrigues (1885-1944) & - La Despedida (Dança chilena $n^{\circ} 2$ ) & 2 \\
\hline $\begin{array}{l}\text { Manuel M. Ponce } \\
(1882-1948)\end{array}$ & - Estrelita (canção mexicana) & 6 \\
\hline M. R. Nunes $(----)^{*}$ & - Noturno & 2 \\
\hline \multirow{2}{*}{$\begin{array}{l}\text { Napoleon Coste } \\
\left(1805^{-1883)}\right.\end{array}$} & - Andantino & 5 \\
\hline & - Estudo $n^{0} 22$ & 1 \\
\hline $\begin{array}{l}\text { Robert de Visée (1655- } \\
1732 / 33)\end{array}$ & - Gavota da Suite em Lá & 1 \\
\hline $\begin{array}{l}\text { Robert Schumann } \\
(1810-1856)\end{array}$ & - Reverie & 4 \\
\hline Rovira (----) & - Romance de amor (estudo) & 1 \\
\hline \multirow[t]{2}{*}{ Villa-Lobos (1887-1959) } & - Choros $n^{0}$ & 4 \\
\hline & - Prelúdio $n^{0} 1$ & 3 \\
\hline $\begin{array}{l}\text { Waldemar Henrique } \\
(1905-1995)\end{array}$ & - Foi Bôto, Sinhá! Toada Amazônica & 3 \\
\hline
\end{tabular}

Figura 2. Tabela com a lista de obras e autores recorrentes em programas de concertos

*Autor até o momento não-identificado. 


\section{Delsuamy Vivekananda Medeiros (1938-2004): relações entre performer e contexto}

Foram 25 compositores observados, os quais podem ser organizados através de 5 tipos de vinculações estéticas:

\begin{tabular}{|c|c|c|}
\hline Vinculação estética-período & Execuções & Compositores \\
\hline \multirow{2}{*}{$\begin{array}{l}\text { Obras de autores barrocos } \\
\text { (transcrições, adaptações, } \\
\text { arranjos) }\end{array}$} & \multirow[t]{2}{*}{13} & $\begin{array}{l}\text { Georg Friederich Häendel (1685-1759), } \\
\text { tocado } 2 \text { vezes }\end{array}$ \\
\hline & & $\begin{array}{l}\text { Johann Sebastian Bach (1685-1750), tocado } \\
11 \text { vezes }\end{array}$ \\
\hline \multirow{3}{*}{$\begin{array}{l}\text { Autores que articulam elemen- } \\
\text { tos da música popular argenti- } \\
\text { na e violão de concerto }\end{array}$} & \multirow[t]{3}{*}{6} & Abel Fleury (1903-1955), tocado 3 vezes \\
\hline & & Juan Rodrigues (1885-1944), tocado 2 vezes \\
\hline & & Antônio Sinopoli (1878-1964), tocado 1 vez \\
\hline \multirow{5}{*}{$\begin{array}{l}\text { Autores brasileiros (ou não, } \\
\text { caso de Sávio) que articulam } \\
\text { elementos da música popular } \\
\text { brasileira e violão de concerto**, } \\
\text { ou autores populares }\end{array}$} & \multirow[t]{5}{*}{15} & $\begin{array}{l}\text { Heitor Villa-Lobos (1887-1959), tocado } 7 \\
\text { vezes }\end{array}$ \\
\hline & & $\begin{array}{l}\text { Waldemar Henrique (1905-1995), tocado } 3 \\
\text { vezes }\end{array}$ \\
\hline & & $\begin{array}{l}\text { Catulo da Paixão Cearense (1863-1946), } \\
\text { tocado } 2 \text { vezes }\end{array}$ \\
\hline & & Dilermando Reis (1916-1977), tocado 2 vezes \\
\hline & & Isaías Sávio (1900-1977), tocado 1 vez \\
\hline \multirow{4}{*}{$\begin{array}{l}\text { Autores românticos não-violo- } \\
\text { nistas (transcrições, adapta- } \\
\text { ções, arranjos) }\end{array}$} & \multirow[t]{4}{*}{16} & Franz Schubert (1797-1828), tocado 5 vezes \\
\hline & & Robert Schumann (1810-1856), tocado 4 vezes \\
\hline & & Isaac Albéniz (1860-1909), tocado 4 vezes \\
\hline & & $\begin{array}{l}\text { Felix Mendelssohn (1809-1847), tocado } 3 \\
\text { vezes }\end{array}$ \\
\hline \multirow{4}{*}{$\begin{array}{l}\text { Compositores-violonistas } \\
\text { clássico-românticos }\end{array}$} & \multirow[t]{4}{*}{29} & Francisco Tárrega (1852-1909), tocado 16 vezes \\
\hline & & Napoleon Coste (1805-1883), tocado 6 vezes \\
\hline & & Fernando Sor (1778-1839), tocado 4 vezes \\
\hline & & Gaspar Sagreras (1838-1901), tocado 3 vezes \\
\hline
\end{tabular}

Figura 3. Tabela com o perfil do repertório a partir da lista de vinculações estéticas

**Ä exceção das obras de Waldemar Henrique, que se trata de uma transcrição, e de Catulo, que se trata, provavelmente de um arranjo.

Nota-se um grande número de autores que possuem ligação com o período Romântico. No entanto, outros aspectos chamam atenção. J. Sebastian Bach é o 
segundo autor mais tocado, demonstrando a importância de ter pelo menos uma obra do compositor barroco nos programas.

Peças de compositores brasileiros eram frequentes, chamando atenção o fato de que praticamente todas articulam diálogos entre elementos considerados como advindos da música popular com formalizações da música considerada como erudita: Choros $n^{0} 1$ de Villa-Lobos; Toada Amazônica de Waldemar Henrique; valsas de Dilermando Reis; e Batucada de Isaías Sávio.

A vinculação com a estética Romântica é evidente pela recorrência de obras de autores românticos não-violonistas como Schumann, Schubert, Mendelsohn e Albéniz, totalizando 16 execuções, e do grande número de obras do espanhol Francisco Tárrega, tocado 16 vezes. Se somarmos a quantidade de execuções relacionadas às categorias de autores românticos não-violonistas e compositores-violonistas clássico-românticos, temos a expressiva soma de 45 . Dessa forma, temos um perfil de repertório que apoia-se consideravelmente na estética romântica.

Essa característica pode estar relacionada a um aspecto discutido por Nogueira (2005). Em sua análise das tendências de repertório do pianismo no Conservatório de Música de Pelotas, observa a eleição de Chopin, por parte dos intérpretes pianistas, a partir da perspectiva de Fernand Braudel:

Teniendo en cuenta que Chopin es un compositor que pertenece a tendencia estética romántica, no podemos dejar de referir que el hecho de que sus obras hayan sido tan fuertemente ejecutadas en el siglo XX recuerda la teoría de la larga duración, de Fernand Braudel. Según Braudel, los hechos en historia no se procesan todos con la misma velocidad, y algunos tardan más en modificarse que otros. Nos parece claro que la fuerte recurrencia de la obra de Chopin en las elecciones de los pianistas lleva a pensar en una permanencia del romanticismo en el siglo XX, en un proceso de larga duración dentro del tiempo de la historia (NOCUEIRA, 2010, p.181).

Embora a escolha de Chopin não esteja somente vinculada ao contexto do Conservatório de Música de Pelotas - tal análise parte de uma premissa cultural mais ampla -, pode-se dizer que tal perspectiva também pode ser considerada no caso de nossa análise.

Por outro lado, ao observarmos o conteúdo de algumas críticas de Sól, nota-se leve tendência a comentar somente obras de autores como Schumann, Schubert, dentre outros. São raros os comentários sobre obras dos compositores brasileiros, por exemplo. Isso decorre também do fato de que suas crônicas, quase que exclusivamente se voltam ao intérprete, ou seja, comentários sobre as qualidades técnico-expressivas de Delsuamy Vivekananda, sempre em tom de relato acerca de suas demonstrações. No entanto, a crítica referente ao concerto do dia 24 de novembro de 1965, no Theatro Sete de Abril (Pelotas), chama atenção pela inclinação cultural-musical contundente do cronista: 
No momento em que êle masculamente alçava aos céus do Romantismo[,] a sempre apaixonante "Serenata" de Schubert, instintivamente pus-me a confrontar - não sei por que associação de idéias - o alinhado perfil daquele moço esgufo e tranquilo, com as grotescas caricaturas humanas dos repugnantemente adamados (peleguinho na nuca, pastinhas ou franjinhas na testa e outros histerismos femininos...) da moderna praga dos 'beatles'[.] que uma certa soberana - até então detentora de unânimes simpatias universais, mas a quem agora estava fazendo falta o velho e duro conselheiro Churchill - desastrosamente galaroou com idênticas condecorações às dos heróis que na guerra haviam arriscado sua vida pela salvação de um Reino periclitante desde Dunkerque... (MúsICA: delsuamy vivekananda, [1966], $[s / p])$.

Embora os comentários preconceituosos de conotação sexual e vinculados à relações de gêneros ("adamados" e "histerismos femininos"), observa-se a clara defesa dos valores estéticos Românticos. Estes evidenciam-se, de certa forma, através da relação entre masculinidade e ascensão aos "céus do Romantismo", exemplificados na execução da Serenata de Schubert, bem como a partir da comparação feita entre o "alinhado perfil do esgufo $^{10}$ e tranquilo" intérprete, valorizando o alinhamento do músico aos valores comportamentais aceitáveis, em contraposição ao perfil cultural e comportamental ("adamados") exemplificado através dos Beatles. Através deste "relato" de Sól, pode-se ter uma dimensão dos valores musicais e comportamentais à época", trazendo uma perspectiva de como as relações de recepção podem estar ligadas ao ponto de vista musical.

Não podemos deixar de mencionar que o processo formativo do intérprete ocorre num período onde a grande maioria dos violonistas esteve em contato constante com os pressupostos técnicos e estéticos da conhecida "Escola de Tárrega", a qual foi difundida em muitos lugares no mundo. No Brasil não seria diferente. Conforme Norton Dudeque, em História do Violão (1994), “um dos precursores do violão moderno no Brasil foi Joaquim Santos (1872-1935) ou Quincas Laranjeiras [...][,] que nos últimos nos de sua vida dedicou-se a ensinar o violão pelo método de Tárrega" (DUDEQUE, 1994, p.102). Além disso, em 1917, a espanhola Josefina Robledo, a qual foi aluna de Tárrega, ao realizar uma tournée no Brasil também atuou como professora, disseminando as premissas de tal escola (DUDEQUE, 1994, p.102). As edições da revista 0 violão (1928-1929) também apontam para o mesmo cenário através dos vários artigos com exercícios atribuídos à "escola" do violonista espanhol.

As composições de Tárrega, além de essencialmente violonísticas “refletem a época em que foram compostas e mostram a influência da música de Chopin, Wagner e Verdi" (DUDEQUE, 1994, p.81). Soma-se a isso, o fato de ter realizado uma série de

10 Possivelmente seja um erro de edição. A nosso ver, sugere a palavra "esguio", uma vez que através das fotos, nota-se que Vivekananda era alto e magro.

11 Não seremos categóricos através de afirmações, uma vez que consideramos que devem ser realizadas mais investigações. 
transcrições, "entre as quais se encontram obras de Albéniz, Bach, Beethoven, Chopin, Mendelsohn, Mozart, Schubert e Schumann" (DUDEQUE, 1994, p.81). Tal processo foi realizado dentro de um contexto onde era necessária a demonstração das possibilidades técnico-expressivas do violão frente ao público e aos compositores (DUDEQUE, 1994, p.83). Possivelmente, as transcrições possam ser consideradas como elementos fundamentais no processo de aceitação do violão e seu repertório dentro das salas de concertos. Pode-se, portanto, observar também a conexão do repertório elegido por Vivekananda com o amplo contexto relacionado a Tárrega, processo este que não pode ser dissociado de sua formação estética e violonística.

A respeito dos valores relacionados à formação do intérprete, uma análise das fotografias de Francisco Tárrega e Delsuamy Vivekananda, pode ajudar na verificação de padrões técnico-posturais comuns:

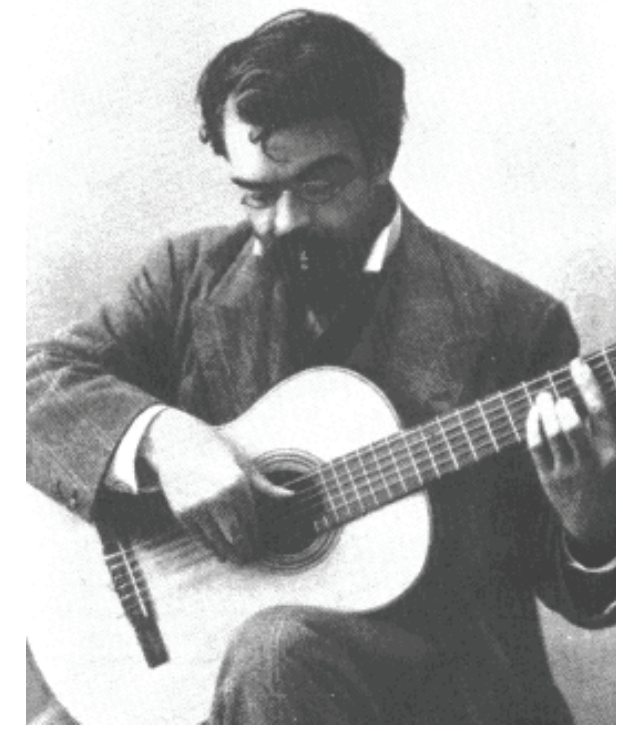

Figura 4. Fotografia de Francisco Tárrega (perfil técnico-postural) $^{12}$

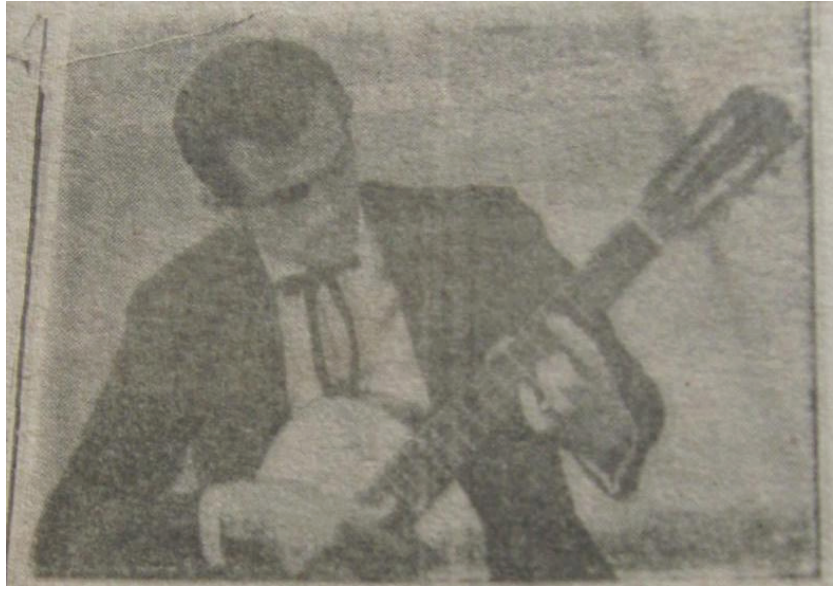

Figura 5. Fotografia de Delsuamy Vivekananda (perfil técnico-postural) ${ }^{13}$

12 Disponível em: 〈http://www.lastfm.com.br/music/Francisco+T\%C3\%A1rrega/+images/309727〉.

13 "Recital de violão". Diário Popular, Pelotas, 9 mai. 1965. [s/p]. 


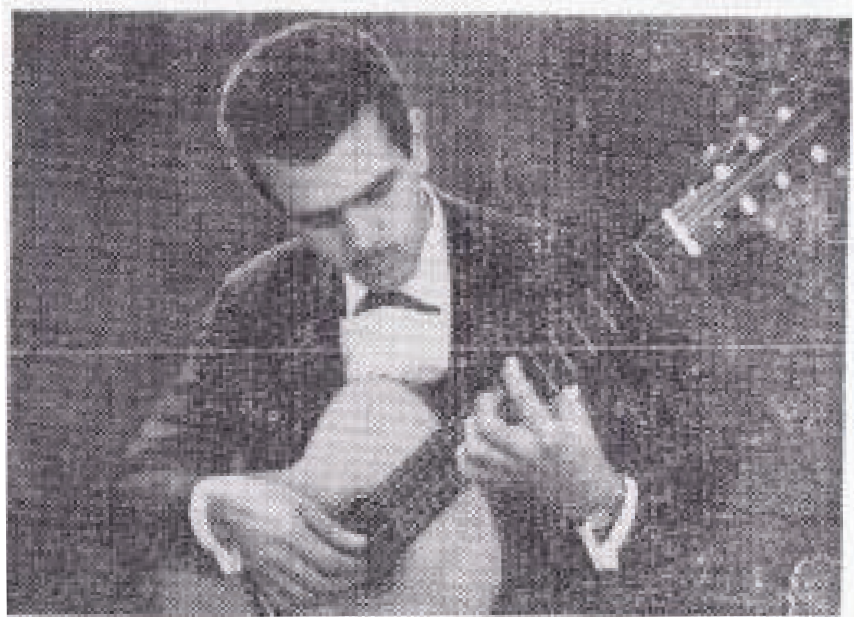

Figura 6. Outra fotografia de Delsuamy Vivekananda (Perfil técnico-postural) ${ }^{14}$

Uma das principais características difundidas da técnica atribuída à Tárrega diz respeito ao posicionamento da mão direita. Conforme Dudeque (1994),

Foi Tárrega quem definiu as bases de técnica moderna do violão. Entre seus méritos está [...] o uso do toque de apoio, em que o dedo da mão direita que pulsa a corda é apoiado na corda imediatamente superior. É sabido que Arcas já usava esse tipo de ataque, mas foi Tárrega que o aperfeiçoou. Essa maneira de pulsar as cordas acarretou mudanças na posição da mão direita. 0 dedo mínimo deixou de ser apoiado no tampo, como era de costume, e a mão direita passou a ser posicionada de forma livre e perpendicular às cordas (Dudeque, 1994, p.80).

Na comparação entre as fotos, observa-se que o posicionamento da mão direita se dá de forma perpendicular, onde as falanges posicionam-se de forma paralela às cordas do violão. Em decorrência disso, pode-se supor que Vivekananda também se utilizava do toque de apoio, como Tárrega preconizava. Além disso, na última foto do violonista pelotense, observa-se que a leve inclinação para cima na postura do ombro direito é muito semelhante à de Tárrega, pela maneira de se posicionar o instrumento. Este aspecto também liga-se à chamada "Escola de Tárrega".

\subsubsection{Considerações preliminares}

As questões levantadas acima revelam um instrumentista que, dentro do processo de escolha acerca do que tocar, identifica-se com premissas estéticas Românticas. Tomando como base as questões levantadas por Nogueira (2010), pode-se dizer que tal perspectiva fazia parte do contexto da época. Isso pode ser explicado pelo fato de que a grande maioria dos instrumentistas nesta época tenha sido orienta$\mathrm{da}$, em seus processos formativos, através de métodos fundamentados em preceitos estéticos clássico-românticos.

14 RECITAL de Violão - Delsuamy Vivekananda, Theatro Sete de Abril, 24 de novembro de 1965. 
0 trecho destacado acerca da crítica de Sól em relação ao concerto de Vivekananda de 24 de novembro de 1965, mostra um pouco do que pode ser tomado como 0 testemunho do gosto do público pelotense, pelo menos àquele circunscrito à ótica de Sól. Isso pode trazer uma ideia sobre parte da atmosfera musical à época na cidade. 0 fato de ser colocado como exemplo de comportamento e postura em relação à presença de palco, por exemplo, apresenta um dos motivos, talvez, das constantes coberturas acerca de suas movimentações.

As relações feitas a respeito da difusão da "Escola de Tárrega" no Brasil e as análises das fotografias em relação ao perfil técnico-postural, tendem a reforçar a vinculação de Vivekananda como um instrumentista cuja identidade liga-se aos pressupostos estético-musicais Românticos.

\section{Considerações finais}

Embora longe de conclusão, acreditamos que nossa pesquisa tem contribuído com 0 amplo processo de compreensão das práticas musicais no contexto do Sul do Brasil, bem como no Rio Grande do Sul e Pelotas. Mais especificamente, o presente trabaIho, visa apresentar uma perspectiva na qual a biografia de um determinado músico não é compreendida de forma isolada, mas sim, dentro de uma rede de relações que contribuíram para tal. No caso de Delsuamy Vivekananda, tomamos as possíveis relações existentes entre músico, imprenssa, rádio, crítica e público como aspectos norteadores do processo interpretativo. Dessa forma, buscou-se não somente informações tidas como objetivas, mas também consideramos as maneiras como estas eram veiculadas, bem como os significados que poderiam ter além da informação em si. Esse aspecto, a nosso ver, apresenta uma pequena dimensão da relação existente entre músico e imprensa. Em síntese, pode-se afirmar que seu papel foi fundamental na consolidação da imagem e representação deste músico, violonista e performer. Mais uma vez, este entendimento amplia a compreensão da construção de sua biografia não como um agente que possui uma gênese tal qual um big-bang, bem como um desenvolvimento divino sem a necessidade de alimentar-se de - e alimentar um contexto, mas de um músico que se consolidou num determinado local e época, a partir de uma série de elementos contribuintes.

Se Delsuamy Vivekananda era notícia, devemos fazer a seguinte reflexão: era notícia pelo fato de distorcer padrões e critérios a respeito das expectativas musicais do contexto (público, imprensa)? Ou era notícia por estar vinculado aos parâmetros tidos como aceitáveis? Acreditamos que era notícia, simplesmente por estar dentro de um contexto e de acordo com padrões artísticos aceitáveis por este meio, pelo menos em termos dos agentes envolvidos com o trabalho de imprensa (seja no papel de produtores, seja no de receptores). Dessa forma, podemos pensar que o perfil do seu repertório, bem como sua identidade musical, eram consonantes ao contexto. Portanto, podemos dizer que a biografia de Delsuamy Vivekananda, no âmbito de 
sua prática como concertista, constrói-se a partir de um círculo cultural-musical onde os mesmos valores são compartilhados entre performer, imprensa e público.

Por outro lado, temos a dimensão de que as reflexões aqui apresentadas constituem-se como apenas uma pequena parte do processo de construção de conhecimento. Pretende-se dar início, futuramente, à perspectiva êmica dentro desta temática. Mais especificamente, será buscada, através da memória e imaginário das pessoas que assistiram às apresentações de Vivekananda, uma dimensão de como estas percebiam o músico, o performer. Em linhas gerais: qual(ais) e como a(s) representação(ões) ligadas ao imaginário destas pessoas constróem a biografia do violonista. Portanto, é a partir da relação entre as dimensões ética e êmica que acreditamos ser possível uma visão aprofundada e abrangente dentro do amplo processo de construção de conhecimento crítico acerca da historiografia musical do Sul do Brasil. 


\section{Referências}

Livros, dissertações, artigos

> ANTÔNIO, Paulo. Sávio homenageado em Pôrto Alegre. Violão e Mestres, São Paulo, n.9, p.27-28, 1968.

> CALDAS, Pedro Henrique. História do Conservatório de Música de Pelotas. Pelotas: Semeador, 1992.

> CASTAGNA, Paulo. Avanços e perspectivas na musicologia histórica brasileira. Revista do Conservatório de Música da UfPel, Pelotas, n.1, 2008. p.32-57.

> CASTAGNA, Paulo. Das linhas de influência à musicologia da vida (prefácio). NOGUEIRA, Isabel Porto; MICHELON, Francisca Ferreira; SILVEIRA Jr., Yimi Walter Premazzi (orgs.). Música, memória e sociedade ao sul: retrospectiva do Grupo de Pesquisa em Musicologia da Universidade Federal de Pelotas (2001-2011). Pelotas, Ed. da UFPel, 2011. p.9-20. ISBN: 978-85-7192-824-4.

> CERQUEIRA, Fábio Vergara; MICHELON, Francisca Ferreira; NOGUEIRA, Isabel Porto; GOLDBERG, Luiz Guilherme Duro; FERREIRA, Maria Letícia Mazzuchi. 0 Centro de Documentação Musical da UFPel no horizonte da multidisciplinaridade: articulações entre musicologia histórica, gestão patrimonial e memória institucional. História [online]. 2008, vol.27, n.2, pp. 111-143.

> DUDEQUE, Norton. História do violão. Curitiba: Ed. da UFPR, 1994.

> GONÇALVES, Pedro Loch; HOLLER, Marcos Tadeu. A atuação de compositores em Desterro no século XIX. Revista do Centro de Artes da UDESC (DAPesquisa), Florianópolis, N.7, 2009-2010. p.354-362.

> HOLLER, Marcos Tadeu. Fontes sobre a história da música em Desterro. Revista do Centro de Artes da UDESC (DAPesquisa), Florianópolis, Vol. 1, 2007-2008. p.1-11.

> NOGUEIRA, Isabel Porto (Org.). História Iconográfica do Conservatório de Música da UFPel. Porto Alegre: Pallotti, 2005.

> NOGUEIRA, Isabel Porto. Piano en la Princesa del Sur - Recepción y circularidad de la música culta para piano en la ciudad de Pelotas (RS, Brasil) 1918-1968. Música, memória e sociedade ao Sul: retrospectiva do Grupo de Pesquisa em Musicologia da UFPel (2001-2011). Pelotas: Editora da UFPel, 2010. p.326.

> SOUZA, Márcio de. 1968: 0 violão chega à faculdade. Assovio, Porto Alegre, n.7, p.5, mar, 2001.

> VICENZI, Anamaria Marques; HOLLER, Marcos Tadeu. A música na imprensa em Desterro durante o Império. Revista do Centro de Artes da UDESC (DAPesquisa), Florianópolis, Vol. 1, 2007-2008. p.1.

\section{Jornais}

> AULAS de violão. Diário Popular, Pelotas, 26 jun. 1965, p.4.

> CONCÊRTO de violão. Diário Popular, Pelotas, 6 jul. 1966, p.4. 


\section{Delsuamy Vivekananda Medeiros (1938-2004): relações entre performer e contexto}

> CURSO de violão. Diário Popular, Pelotas, 281 abr. 1967, p.4.

> CURSO de violão: começa hoje. Diário Popular, Pelotas, 3 mai. 1967, p.4.

> DELSUAMY atuou na prh-2 e na tv-piratini: p. alegre!. Diário Popular, Pelotas, 14 jul. 1960. p.4.

> DELSUAMY vai ensinar violão no conservatório. Diário Popular, Pelotas, 21 abr. 1967, p.4.

> DELSUAMY Vivekananda Atuará, Hoje, Na Rádio 'El Espectador'. Diário Popular, Pelotas, 12 jun. 1965, p.4.

> DELSUAMY Vivekananda fará excursão no mês vindouro!. Diário Popular, Pelotas, 5 jun. 1966, p.4.

> DELSUAMY Vivekananda foi apaludido de pé: recitais - Seguiu, hoje, para Montevidéu. Diário Popular, Pelotas, 6 jun. 1965, p.4.

> DELSUAMY vivekananda, hoje, na soc. libanesa: hora de arte a cargo do jovem e exímio violonista. Diário Popular, Pelotas, 11 jun. 1960. p.4.

> DELSUAMY vivekananda: una passion, la guitarra. [El Paiz], [Montevideo], [s/d]. [1965], p.[s/p].

> GUITARRISTA vivekananda. Diário Popular, Pelotas, 19 jun. 1966, p.4.

> HOJE o recital de violão de delsuamy vivekananda. Diário Popular, Pelotas, 18 jun. 1963. p.4.

> INSCRIÇÕES para o curso de violão no conservatório. Diário Popular, Pelotas, 23 abr. 1967, p.4.

> MÚSICA: delsuamy vivekananda. [Diário Popular], [Pelotas], [1966], [s/p].

> NOTAS de arte: vivekananda medeiros. Diário Popular, Pelotas, 3 jul. 1960. p.4.

> RECITAL de delsuamy. Diário Popular, Pelotas, 24 jun. 1966, p.4.

> RECITAL de delsuamy amanhã. Diário Popular, Pelotas, 5 jul. 1966, p.4.

> RECITAL de violão". Diário Popular, Pelotas, 21 jun. 1963. contracapa.

> Sól. Música: Recital de violão. Diário Popular, Pelotas, 21 jun. 1963. p.4.

> VIVEKANANDA: 3 recitais na "semana de p. alegre". Diário Popular, Pelotas, 6 nov. 1966, p.4.

\section{Programas de concertos:}

> CONSERVATóRIO de música: jubileu de ouro (1918-1968), Auditório do Conservatório de Música, 18 de junho de 1968.

> LICEU musical palestrina: Apresenta o seu 1ć festival de violão, Teatro São Pedro, 30 de julho de 1967.

> PREFEITURA municipal de pôrto alegre: delsuamy vivekananda, Teatro São Pedro, 27 de março de 1967. 
> RECITAL de Violão - Delsuamy Vivekananda, Conservatório de Música, 1968.

> RECITAL de Violão - Delsuamy Vivekananda, Teatro Gonzaga, 6 de julho de 1966.

> RECITAL de Violão - Delsuamy Vivekananda, Theatro Sete de Abril, 24 de novembro de 1965.

> RECITAL de violão com Delsuamy Vivekananda, Auditório do Colégio São José, 3 de junho de 1965.

> RECITAL de violão: Delsuamy Vivekananda, Auditório do Conservatório de MúsiCa, 19 de dezembro de 1968.

> SEMANA de Pôrto Alegre: Recital de violão à cargo de Delsuamy Vivekananda, [sem local], [1966].

\section{E-mail:}

> ESCANDE, Alfredo. Pergunta respondida. “[mensagem pessoal]”. Mensagem recebida por e-mail em 30 de Junho de 2009, às 23:01:55.

Daniel Ribeiro Medeiros, Bacharel em Música - Habilitação em Violão pela Universidade Federal de Pelotas (2004) e Mestre em Música (Interpretação/ Processos Criativos: Teoria, Criação Musical e Estética) pela Universidade federal do Paraná (2010), sob orientação do Prof. Dr. Norton Dudeque. Em suas pesquisas, tem abordado temáticas relacionadas a Teoria e Análise Musical e historiografia musical juntamente a aspectos culturais. São trabalhos que envolvem investigações no âmbito da chamada música "culta" e música popular, tal como rock progressivo e minimalismo, processos interpretativos (performance culturalmente-historicamente informada), bem como pesquisas em torno da prática do violão em Pelotas e Rio Grande do Sul. Atualmente, atua como professor temporário no curso de Música - Modalidade Licenciatura da Universidade Federal de Pelotas (UFPel).

drmedeiros25@yahoo.com.br 